\title{
DESONERAÇÃO DA FOLHA DE PAGAMENTOS : DETERMINANTES E CONSEQUENCIAS
}

\section{EXONERATION OF THE PAYROLLS: CAUSES AND CONSEQUENCES}

\author{
${ }^{1}$ Eliseu Sampaio Nogueira
}

\section{RESUMO}

A carga tributária tem sido objeto de intensos debates nas últimas duas décadas. Com a política de desonerações da folha de pagamentos esperou-se aliviar o peso dos tributos no Brasil. Implementou-se a substituição da contribuição patronal sobre a folha de pagamentos pela incidência sobre o faturamento. Avaliou-se o impacto de tais medidas sobre a economia e as várias alterações legislativas. A maneira como foi feita a desoneração sobre a folha de pagamentos foi considerada errônea sobre o ponto de vista jurídico e econômico.

Palavras-chave: Carga tributária, Desonerações da folha de pagamentos, Contribuição patronal, Faturamento

\begin{abstract}
The tax burden has been object of intense discussion in the last two decades. Within of the politic of payroll exoneration, it was expected to relieve the burden of tax in Brazil. It was implemented the replacement of the employer's contribution by the incidence on invoice revenue. It was evaluated the impact of these measures on the economy and the several legislative modifications. The way of how was implemented the payroll exoneration was considered wrong under the legal and economic perspective.
\end{abstract}

Keywords: Tax burden, Payroll exoneration, Employer's contribution, Invoice revenue

\footnotetext{
${ }^{1}$ Mestre em Direito pela Universidade Federal do Ceará - UFC, Ceará (Brasil). E-mail: eliseusn@ uol.com.br
} 


\section{INTRODUÇÃO}

O Brasil tem sido marcado, sobretudo nas duas últimas décadas, por uma intensa discussão acerca da carga tributária, notadamente sobre o alto custo de se contratar no País, tendo em vista os tributos incidentes sobre a folha de pagamentos.

Inicialmente, procuraremos esclarecer aspectos sobre a carga tributária suportada pelos brasileiros nos últimos anos não deixando de mencionar as bases sobre as quais incidem os tributos no Brasil.

O governo da presidenta Dilma Roussef (2011), tem sido marcado por uma forte desconcentração de tributos sobre a folha de pagamentos, havendo uma transferência dessa incidência para o faturamento das empresas, fenômeno esse iniciado ainda sob o governo anterior.

Essa transferência levou os empregadores a deixarem de recolher a contribuição social sobre a folha de pagamentos, passando os mesmos a recolher sobre uma outra base, qual seja, o faturamento ou a receita bruta.

Diante disso, teceremos várias considerações sobre a estrutura jurídica da seguridade social, suas origens e fonte de recursos. A par disso, verificaremos a composição do salário e as contribuições incidentes sobre este.

Dando seguimento ao estudo das contribuições sociais, mostraremos o mecanismo de cálculo da cumulatividade e da não-cumulatividade, os conceitos de faturamento e receita e o arcabouço normativo das contribuições.

Por fim, e objetivo maior deste trabalho, discutiremos como a desoneração sobre a folha foi feita, as alterações legislativas e os impactos na arrecadação tributária.

A conclusão a que se chegou foi a de que a desoneração da folha de pagamentos, em que pese seus objetivos tenham sido o de uma melhoria das condições do País de gerar riqueza e aumentar a força laboral formal, foi e está sendo realizada de uma forma errônea, pois desprezou princípios constitucionais e exagerou na medida de seu montante. 


\section{CONSIDERAÇÕES SOBRE A CARGA TRIBUTÁRIA BRASILEIRA. AS BASES TRIBUTÁRIAS.}

Buscando-se informações junto ao Direito Financeiro (J. R. Caldas Furtado, 2010), podemos classificar as receitas estatais, quanto a sua origem, em originárias e derivadas. As receitas originárias decorrem da exploração, pelo Estado, de seus próprios bens. A receita derivada advém da investida estatal sobre o patrimônio do particular, e essa investida pode ser expressa por meio dos tributos e sanções.

Já na obra de Régis Fernandes de Oliveira (2010,p. 123), podemos ver uma outra fonte de receita, denominada Transferidas, as quais, segundo o autor, são arrecadadas pela pessoa jurídica competente para a tributação, mas a ela não pertencem, devendo ser transpassadas a outras pessoas jurídicas menores ( Estados e Municípios).

O que nos interessará no presente capítulo são as Receitas Derivadas, das quais os tributos são sua espécie, não somente os dispostos no Sistema Tributário Nacional, mas também as contribuições elencadas no art. 195 da Constituição da República. Esses tributos, distribuídos nas esferas do Estado brasileiro, União, Estados, Distrito Federal e Municípios compõem a arrecadação tributária brasileira, ou a tão propalada carga tributária.

Quando veiculada que a carga tributária brasileira está alta ou está entre uma das maiores do mundo, entende-se a relação da carga tributária com o Produto Interno Bruto - PIB, que significa o cômputo de todas as riquezas geradas pelo País. Essa é a forma mais usual de se demonstrar a expressão carga tributária, embora existam outras, como, por exemplo, a carga de tributos de um país em função da base de incidência. Sobre as bases de incidência falaremos no próximo tópico.

O cômputo da carga tributária bruta - C. T. B em função do PIB dá-se pela seguinte equação:

C. T. $\mathrm{B}=[($ Arrecadação Tributária da União, Estados, DF e Municípios)/PIB]x 100

A seguir, temos a distribuição da C.T.B, expressa em porcentagem, ao longo dos anos 2000 a 2009:

Revista de Direitos Sociais, Seguridade e Previdência Social| e-ISSN: 2525-9865 | Brasília |v. 2 | n. 1 | p. 174-192 | Jan/Jun. 


\section{Gráfico 1}

$(\mathbf{E m} \%)$

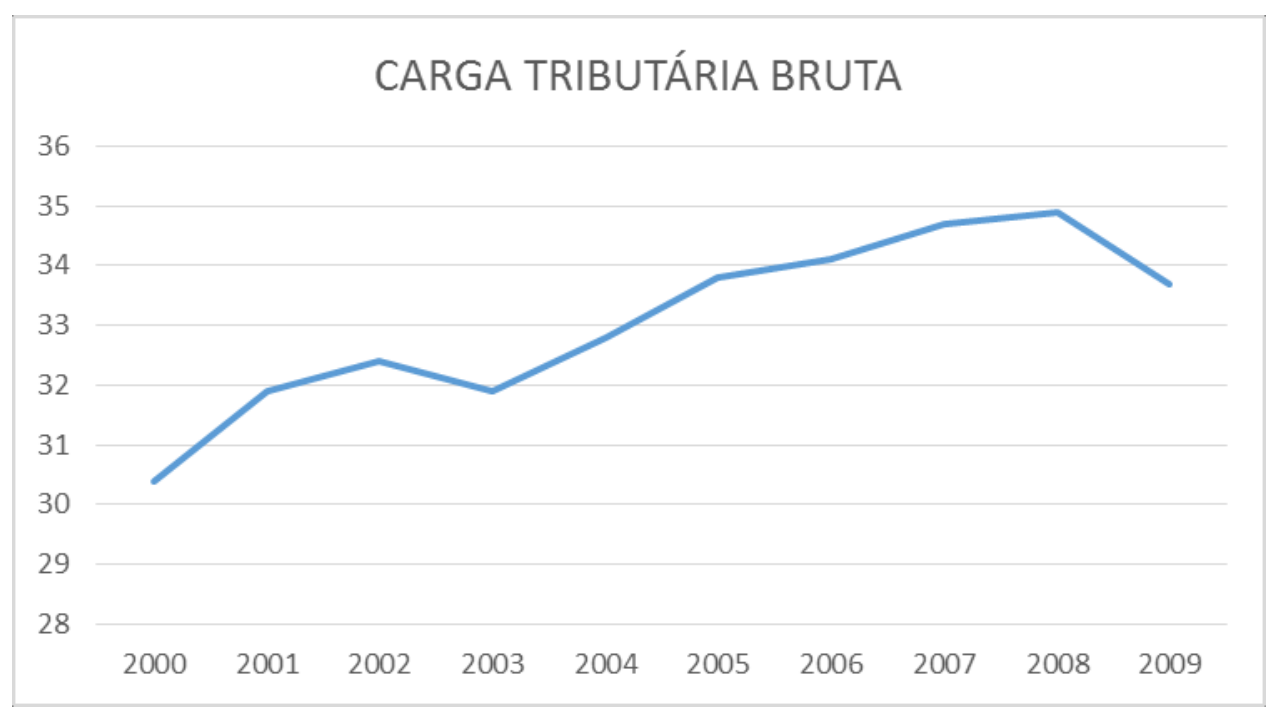

Fonte: IBGE. Séries Históricas e Estatísticas.

O conceito de Carga Tributária Bruta, no entanto, pode ser relativizado por conta do conjunto de transferências e subsídios previstos no S. T. N - Sistema Tributário Nacional e na política fiscal que orienta os gastos públicos. Temos, então, o conceito de Carga Tributária Líquida, que corresponde à C. T. B deduzidas dessas transferências e subsídios. Entende-se por transferências as pensões e aposentadorias e outros benefícios previdenciários e assistenciais para, por exemplo, idosos e mais pobres e/ou portadores de deficiências.

Além das transferências e subsídios, há que se considerar também no conceito da carga tributária líquida os pagamentos de juros da dívida pública.

\subsection{Bases Tributárias}

As bases tributárias ou bases de arrecadação são os pilares sobre os quais os sistemas tributários se apoiam. Não somente no Brasil mas em quase todos os países, essas bases correspondem à renda, ao consumo e produção de bens e serviços, à folha de salários e ao patrimônio.

Essa distribuição da arrecadação tributária expressa o meio pelo qual sociedade e Estado convergiram em um determinado momento histórico no que tange ao financiamento do próprio ente estatal advindo de receitas daquela mesma sociedade. 
No Brasil, como iremos observar, a distribuição do peso dos tributos está mais concentrada na produção e consumo de bens e serviços. Uma parcela significativa também é arrecadada na folha de pagamentos. Ainda que a tributação sobre a folha, por meio das contribuições sociais, tenha finalidade meritória, pois financia a Seguridade Social, é um tributo que também é repassado aos preços dos bens e serviços, a exemplo dos tributos incidentes sobre a produção e consumo.

Num estudo sobre a distribuição da C.T.B pela base de incidência no ano de 2008, o IBGE - Instituto Brasileiro e Geografia e Estatística, citado pelo DIEESE Departamento Intersindical de Estatística e Estudos Sócio-Econômicos , IPEA Instituto de Pesquisa Econômica Aplicada e Sindifisco - Sindicato dos Auditores Fiscais da Receita Federal do Brasil, revelou a porcentagem da carga por base de incidência, no ano de 2008. Senão vejamos:

\section{Gráfico 2}

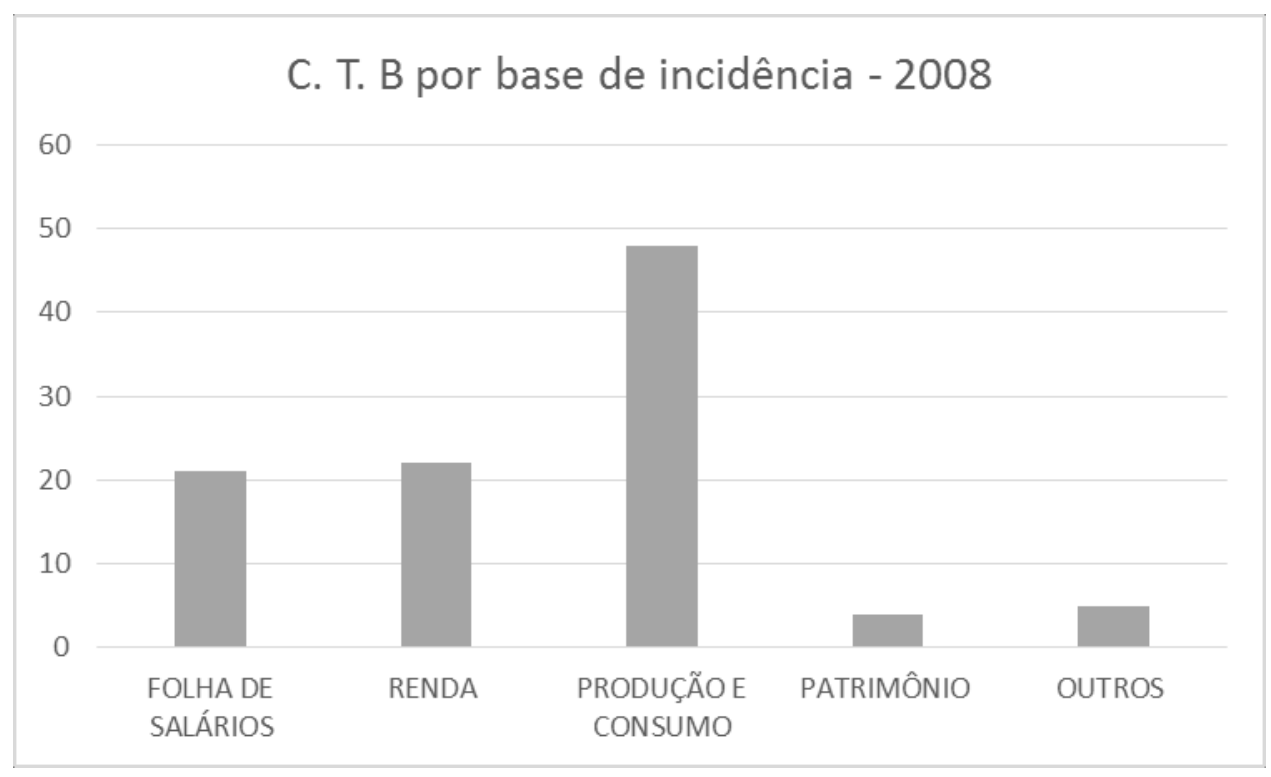

Fonte: IBGE. Contas Nacionais; Observatório da Equidade. 
Os gráficos dispostos acima mostram, sinteticamente, de que forma e o quantum o Estado arrecada (política tributária). No entanto, a forma de gastar (política fiscal) também deve ser considerada quando da avaliação da combinação arrecadação versus gasto público. Embora não seja esse o objetivo desse trabalho, cumpre mencionar que a concentração da arrecadação nas bases da folha de pagamentos e produção e consumo aliados a aspectos de uma menor equidade do sistema tributário tornam o Brasil um país com um das cargas tributárias mais injustas do mundo.

\section{O SISTEMA DA SEGURIDADE SOCIAL. ORIGENS. AS CONTRIBUIÇÕES SOCIAIS NA CONSTITUIÇÃO DA REPÚBLICA BRASILEIRA.}

$\mathrm{O}$ início da proteção securitária garantida à população pelo Estado teve sua origem na Alemanha do século XIX, onde o então chanceler Bismarck obteve a aprovação pelo parlamento para seu projeto de seguro doença, seguido pelo seguro de acidentes de trabalho (1884) e pelo seguro de invalidez e velhice (1889).

Essa época marcou a $1^{\mathrm{a}}$ fase ou fase inicial evolutiva da previdência social, segundo o autor Fábio Z. Ibrahim (2013, p.45). O autor ainda afirma que, apesar de não haver consenso sobre as fases evolutivas, a mais usual seria

Fase inicial (até 1918): criação dos primeiros regimes previdenciários, com
proteção limitada a alguns tipos de eventos, como acidentes de trabalho e
invalidez; Fase intermediária (1919 a 1945): expansão da previdência pelo
mundo, com a intervenção do Estado cada vez maior na área securitária; Fase
contemporânea (a partir de 1946): aumento da clientela atendida e dos
benefícios. É o grau máximo do Welfare State, com a proteção de todos
contra qualquer tipo de risco social.

No Brasil, atualmente vigoram os chamados diplomas básicos da Seguridade Social: a Lei 8.212/91 (Plano de Custeio e Organização da Seguridade Social) e Lei 8.213/91 (Plano de Benefícios da Previdência Social), seguidos do Regulamento da Previdência Social (aprovado pelo Decreto $n^{\circ} 3.048 / 99$ ), que regulamenta disposições relativas ao custeio da seguridade e aos benefícios da previdência social, com as alterações subsequentes. 


\subsection{Seguridade Social. Contribuições Sociais. Arcabouço normativo}

A Constituição da República traz em seu Título VIII, Capítulo II, disposições gerais e a estrutura sobre a qual se assenta a Seguridade Social, a saber: Saúde, Previdência Social e Assistência Social.

Bem estruturada que foi e considerada como um dos sistemas mais avançados do mundo, no que tange ao universo de atendimento e à disposição de suas normas, a Seguridade Social, como conjunto integrado de ações de iniciativa dos Poderes Públicos e da sociedade (art. 194, CF/88), tem como mandamentos nucleares de suas ações os seguintes princípios: universalidade de cobertura e atendimento; uniformidade e equivalência dos benefícios e serviços às populações urbanas e rurais; seletividade e distributividade na prestação dos benefícios e serviços; irredutibilidade do valor dos benefícios e serviços; equidade na forma de participação no custeio; diversidade da base de financiamento e caráter democrático e descentralizado da administração.

A Saúde, na expressão do art. 196 da CF/88 é direito de todos e dever do Estado. Logo, independentemente de contribuições, todos têm direito à atendimento médico na rede pública, não importando seu patrimônio.

A Assistência Social, a seu turno, por força do art. 203 da Constituição Federal, é prestada a quem dela necessita, independente de contribuição direta do beneficiário.

Por sua vez, a Previdência Social (art. 201, CF/88) é organizada sob a forma de regime geral, de caráter contributivo e filiação obrigatória, observados os critérios que preservem o equilíbrio financeiro e atuarial.

Feita essa breve explanação, trataremos agora de buscar na Constituição da República os pontos determinantes da instituição das Contribuições Sociais.

Em seu art. 149, a nossa Carta Magna dispôs sobre a competência exclusiva da União no que trata da instituição de tais contribuições, todavia o mesmo diploma faz menção, em seu art. 195, que a Seguridade Social será financiada por toda a sociedade, de forma direta e indireta, e pelas seguintes contribuições sociais: 


\title{
Quadro 1
}

\begin{tabular}{|l|} 
Empregadores, empresa e equiparados \\
Incidência sobre $\left\{\begin{array}{l}\text { - Lucro } \\
\text { - Faturamento ou Receita } \\
\text { - Folha de salários ou qualquer pagamento que a pessoa física } \\
\text { receba pelo seu trabalho }\end{array}\right.$ \\
Trabalhadores e outros segurados da Previdência \\
Receita de concurso de prognósticos
\end{tabular}

Na melhor exegese do supracitado art. 149, o professor Hugo de B. Machado (2015, p. 171), assim entende:

\begin{abstract}
Isso significa dizer que essas contribuições sociais caracterizam-se pela correspondente finalidade. Não pela destinação do produto da respectiva cobrança, mas pela finalidade da instituição, que induz a ideia de vinculação de órgãos específicos do Poder Público à relação jurídica com o respectivo contribuinte. (....) Diante da vigente Constituição, portanto, pode-se conceituar a contribuição social como espécie de tributo com finalidade constitucionalmente definida - a saber, intervenção no domínio econômico, interesse das categorias profissionais ou econômicas e seguridade social.
\end{abstract}

Uma ressalva à competência exclusiva da União para instituição das Contribuições Sociais é trazida até nós pelo $\S 1^{\circ}$ da Constituição da República quanto à possibilidade de Estados, Distrito Federal e Municípios instituírem contribuições, cobrada de seus servidores, para o custeio, em benefício destes, do regime previdenciário de que trata o art. 40 da Constituição Federal. 


\subsection{As Contribuições sobre a folha de pagamentos}

Antes de adentrarmos no estudo das contribuições sobre a folha de pagamentos, façamos uma breve digressão sobre o destino da arrecadação das Contribuições para a Seguridade Social, inclusa nessas a própria contribuição sobre a folha de pagamentos.

A teor do disposto no art. $165, \S 5^{\circ}$ e 194 , VII , da Constituição da República, o orçamento da seguridade social ganhou autonomia, pois está separado do orçamento fiscal e do orçamento de investimentos, todos esses compondo a lei orçamentária anual.

Isso se faz por demais importante tendo em vista que o orçamento da seguridade social não se confunde com o do Tesouro Nacional, implicando, como diz o jurista Hugo de B. Machado (2015, p.427), que a sua execução não constituiria atribuição do Poder Executivo.

Todavia, com a alteração no âmbito da própria Constituição Federal, em seu art. 195, I e II, por conta da Emenda Constitucional 20/1998, que equiparou à empresa outras entidades na forma de lei ordinária, fica muito a depender de lei o âmbito constitucional de tais contribuições.

Ainda segundo o citado jurista, temos

As contribuições, com as quais os empregadores, os trabalhadores e os administradores de concursos de prognósticos financiam diretamente a seguridade social, não podem constituir receita do Tesouro Nacional precisamente porque devem ingressar diretamente no orçamento da seguridade social. Por isso mesmo, lei que institua contribuição social com fundamento no art. 195 da CF indicando como sujeito ativo pessoa diversa da que administra a seguridade social viola a Constituição. Ressalte-se que não se trata de saber qual o destino das contribuições de seguridade social. Não se trata, apenas, de um problema de Direito Financeiro. Trata-se de saber quem é o sujeito ativo dessas contribuições - e, a nosso ver, o sujeito ativo das mesmas é a entidade responsável pela gestão do orçamento a que se refere o art. $165, \S 5^{\circ}$, III, da CF. Em outra palavras, o INSS - autarquia que ganhou o patamar constitucional e que deve ser aperfeiçoada de modo a realizar completamente o preceituado no art. 194 da CF. Ocorre que o STF decidiu ser possível a cobrança da COFINS e da CSL pela União, que atuaria como

Revista de Direitos Sociais, Seguridade e Previdência Social| e-ISSN: 2525-9865 | Brasília |v. 2 | n. 1 | p. 174-192 | Jan/Jun. 


\begin{abstract}
simples intermediária, e repassaria os recursos correspondentes ao INSS. Em consequência, ditas contribuições foram convertidas em verdadeiros impostos, dos quais a União repassa para o INSS apenas o necessário para cobrir o déficit orçamentário daquela autarquia, que seria superavitária se lhe fosse permitido arrecadar todas as contribuições que a Constituição de 1988 atribuiu à seguridade social. Estimulado, talvez, pela decisão do STF que lhe permitiu apropriar-se de receitas da seguridade social, o Governo conseguiu do Congresso Nacional a Lei 11.457, de 16.3.2007, criando a Receita Federal do Brasil, órgão no qual foram unificadas as atividades de arrecadação dos tributos federais e das contribuições de seguridade social.
\end{abstract}

Reza o disposto na Constituição da República (art.195, I) que uma das bases de cálculo da contribuição social para a seguridade social a cargo do empregador, empresa e da entidade a ela equiparada é a folha de salários e demais rendimentos pagos ou creditados, a qualquer título, à pessoa física que lhe preste serviço, mesmo sem vínculo empregatício. Pois bem. E o que se entende por folha de salários, grosso modo?

Folha de salários, seria, pois, a soma dos salários recebidos por todos os empregados da empresa. No entanto, a contribuição patronal não incide somente sobre a remuneração de empregados mas também sobre a dos avulsos. É de $20 \%$ a alíquota sobre o total das remunerações pagas, creditadas ou devidas, a qualquer título, durante o mês, aos segurados empregados e trabalhadores avulsos que the prestem serviços, destinadas a retribuir o trabalho, qualquer que seja a sua forma, inclusive as gorjetas, ganhos habituais sob a forma de utilidades e adiantamentos decorrentes de reajuste salarial, quer pelos serviços efetivamente prestados, quer pelo tempo à disposição do empregador ou tomador de serviços.

Uma outra contribuição, também na razão de $20 \%$ sobre o total das remunerações pagas ou creditadas a qualquer título, no decorrer do mês, é aquela relativa ao contribuinte individual. Existem outras contribuições incidentes sobre a folha de salários, como por exemplo, o SAT - Seguro sobre Acidentes de Trabalho e há também o adicional pago pelo setor financeiro e seguradoras $-2,5 \%$. À guisa de exemplo, mostraremos as alíquotas de encargos sociais incidentes sobre a folha de pagamentos média mensal das empresas, elaborada pelo Dieese e citada na obra Proguessividade da Tributação e Desoneração da Folha de Pagamentos (2011): 


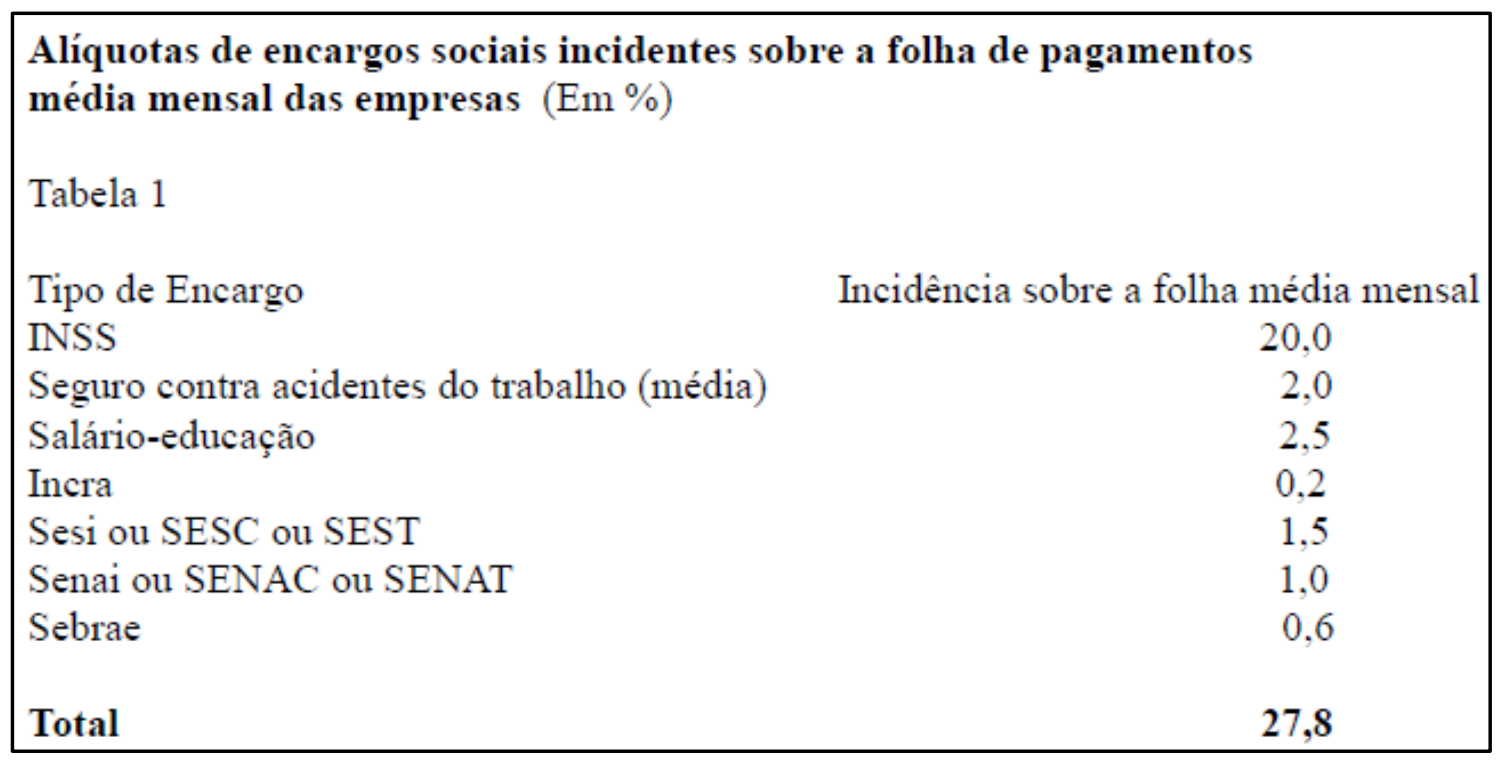

Fonte: Guia do INSS. Elaboração: Dieese.

Por fim, reitere-se que a base de cálculo das retrocitadas contribuições são todas as parcelas remuneratórias, isto é, tudo o que for pago em decorrência da contraprestação do serviço prestado pelo trabalhador. Restam, portanto, excluídas as parcelas de natureza indenizatória e ressarcitória. Nesse sentido, temos o art. 201, §11 da CF/88 e a Lei $n^{\circ} 8.212 / 91$, art.28, $\$ 9^{\circ}$.

\subsection{Cumulatividade e não-cumulatividade}

Há duas modalidades de incidência sobre o faturamento para algumas contribuições sociais, por exemplo, PIS e COFINS: cumulativa e a não-cumulativa.

$\mathrm{Na}$ incidência cumulativa, as contribuições são devidas em cada fase do processo de produção, sendo que não é permitido aos contribuintes recuperarem a contribuição paga em etapas anteriores ( Neves e Viceconti, 2013).

Já na incidência não-cumulativa, pode-se abater o que foi pago a título dessas contribuições com o devido em etapas posteriores, como ocorre, por exemplo, com o ICMS e o IPI.

Vale observar o seguinte: contabilmente, receita bruta e faturamento são conceitos distintos, pois enquanto o faturamento representa o total das vendas incluso o IPI, na Receita Bruta tal imposto não está incluso. Porém, para fins de incidência das contribuições sociais (art. 195, I, b, CF/88), ambas as palavras têm o mesmo significado. 


\section{ANÁliSE DA DESONERAÇÃO DA FOLHA DE PAGAMENTOS. IMPACTOS DO ATUAL MODELO E ALTERAÇÕES POSTERIORES.}

Em agosto de 2011, o Governo Federal lançou, por intermédio do plano Brasil Maior, uma modalidade de desoneração da folha de pagamentos que substitui integralmente a contribuição patronal de $20 \%$ sobre a folha de pagamentos por uma outra contribuição social incidente sobre o faturamento.

Os setores inicialmente contemplados e a sequencia dos diversos atos normativos que deram continuidade à desoneração serão tratados num tópico mais adiante.

\subsection{Origens da discussão em torno do tema desoneração da folha de pagamentos}

Quando se discutem alternativas de políticas públicas, vem à tona a proposta de desoneração da folha de pagamentos, como meio de reduzir os custos do empregador e aumentar a competividade empresarial a nível internacional.

Toda essa discussão traz a reboque o problema do financiamento da maioria dos Estados na atualidade, visto que a folha de pagamentos traduz importante fonte de arrecadação, utilizada de modo proporcionalmente mais intenso conforme o desenvolvimento das políticas previdenciárias ou de bem-estar social vigentes no País. A destinação predominante dos recursos arrecadados sobre a folha de pagamentos, em geral, financia as políticas de seguridade social.

Ainda em torno dessa discussão, gravitam argumentos prós e contras à desoneração da folha, pois o debate sobre os encargos sociais no Brasil traz embutido uma grande controvérsia acerca do impacto que uma eventual redução destes teria sobre o mercado de trabalho, em termos de nível de qualidade e emprego.

Num importante estudo sobre o tema, Alberto Luchiezi Jr. (2011, p.86), enumera alguns argumentos favoráveis à desoneração, senão vejamos. O primeiro deles seria que esta estimularia a competividade das empresas beneficiadas, via redução custos de produção. Adicionalmente, complementa o autor, a desoneração serviria como estímulo à formalização de parte de mão-de-obra desocupada ou alocada no mercado informal de trabalho. As perdas de receita previdenciárias seriam compensadas com o maior volume de contribuições dos trabalhadores formalizados.

Num mesmo sentido, Carlos Rodrigues de Oliveira (2011, p.75), destaca que os defensores da desoneração consideram muito elevados os encargos sociais e que, 
somados à magnitude e à rigidez que esses encargos possuem, os mesmos dificultariam a ampliação do número de empregos e gerariam um elevado grau de informalização dos vínculos de trabalho.

Por outro lado, há os que consideram que os encargos representam pouco mais de um quarto da remuneração total recebida pelo trabalhador e que uma grande parcela de que se costuma chamar de encargo social é, na verdade, parte integrante da própria remuneração. Além do que, os fatores inibidores do crescimento muito mais importantes que o peso dos encargos sociais estariam situados em outra esfera, ligada às condições macroeconômicas que inibem o investimento e a demanda interna (Carlos Rodrigues de Oliveira (2011, p.76).

Ainda na mesma obra, Alberto Luchiezi Jr. afirma, como contraponto aos argumentos favoráveis à desoneração, o fato de não terem sido formulados modelos que avalizem os argumentos e que não foram feitas estimativas quanto ao emprego formal a ser criado sobre o volume de contribuições resultantes ou quanto à expansão da massa salarial necessária para incrementar a arrecadação.

Segundo esse mesmo autor, não existem indicações de como a melhoria da arrecadação total seria canalizada para suprir as perdas na arrecadação previdenciária e que sequer foi mencionado o hiato temporal entre as perdas na arrecadação e os efeitos benéficos da melhoria da competividade e da formalização da mão-de-obra.

Pois bem. Dentro de um amplo espectro de discussões sobre os motivos incialmente colocados como determinantes à concessão das desonerações, devemos atentar para os seguintes fatores como cruciais à efetividade das medidas: os efeitos sobre a carga tributária, as contrapartidas ao orçamento da seguridade social e os critérios jurídico-econômicos escolhidos.

Não se pode, às custas do orçamento da seguridade social (art. $165, \S 5^{\circ}$ ), que independe dos outros orçamentos, fazer concessões a setores da iniciativa privada, como vem acontecendo, sem uma correta e rápida contrapartida.

Também não há como concordar com mais aumento de carga tributária num País como o nosso, marcado por tantas desigualdades.

Outro ponto interessante, é a discussão sobre quais os setores a serem beneficiados, a forma como está sendo feita e a segurança jurídica que deve permear toda essa política de concessões. 


\subsection{Alterações legislativas. Medidas de desoneração da folha}

A fim de uma maior visão sobre o elenco das principais modificações introduzidas pelos diversos atos que compuseram as medidas desonerativas, mostraremos a evolução das medidas de desoneração da folha de pagamentos (Airton Nagel Zanghelini et al, 2013):

a) Medida Provisória ${ }^{\circ} 540$, de 02/08/2011

Transformou a incidência da contribuição previdenciária patronal para o faturamento, a substituição alcançou as empresas que prestam exclusivamente serviços de Tecnologia da Informação - TI e de Tecnologia de Informação e Comunicação TIC e, também, empresas fabricantes de vestuário e seus acessórios, artigos têxteis, calçados, chapéus e couros;

b) Lei $n^{\circ} 12.546$, de 14/12/2011. Conversão da MP nº 540

Determinou que a União compense o Fundo do Regime Geral de Previdência Social , " no valor correspondente à estimativa de renúncia previdenciária decorrente da desoneração, de forma a não afetar a apuração do resultado financeiro da Previdência";

c) Medida Provisória n ${ }^{\circ}$ 563, de 03/04/2012

Alterando a Lei $\mathrm{n}^{\mathrm{o}}$ 12.546/2011, a MP 563 trouxe novas medidas de desoneração, estendendo o benefício para empresas do setor hoteleiro, outros serviços, bem como ampliou significativamente o rol dos produtos abrangidos, com base na Tabela de Incidência do Imposto sobre Produtos Industrializados - TIPI.;

d) Lei no 12.715, de 17/09/2012. Conversão da MP n 563

Uma inovação importante do Projeto de Lei de Conversão - PLV assegura que as renúncias associadas à desoneração da folha de pagamentos serão cobertas com transferências do Orçamento Fiscal;

e) MP 582, de 20/09/2012, convertida na Lei $n^{\circ} 12.794$, de 02/04/2013 
Alterou o cálculo da contribuição patronal para as empresas que estão submetidas ao duplo mecanismo de cálculo (recolhem sobre a folha de pagamentos para os produtos não desonerados e sobre o faturamento para os produtos desonerados);

f) $M P n^{\circ} 601$, de 28/12/2012

Com vigência a partir de 01 de abril de 2013, foram incluídas empresas do setor de construção civil, empresas comerciais de varejo e ampliado o rol dos produtos abrangidos, com base na tabela TIPI.;

g) MP no 612, de 04/04/2013

A quase totalidade dos disciplinamentos, atividades e produtos contemplados na Medida Provisória n ${ }^{\circ} 612$ foi incluída no Projeto de Lei de Conversão no 17, de 2013, que definiu a redação final da MP $n^{\circ} 610$, de 02 de abril de 2013, convertida na Lei $n^{\circ}$ 12.844, de 19 de julho de 2013;

h) Lei $n^{\circ} 12.844$, de 19 de julho de 2013. Conversão da MP no 610

Foram incluídas na contribuição substitutiva vários fabricantes de diversos itens, como suportes para camas, passando por absorventes e tampões higiênicos, fraldas para bebês até construção de obras para infraestrutura, enquadradas nos grupos 421, 422, 429 e 431 da CNAE 2.0 - 01.01.2014;

i) Lei $n^{\circ} 12.873$, de 24 de outubro de 2013

Foram excluídas da contribuição substitutiva: empresas de varejo dedicadas exclusivamente ao comércio fora de lojas físicas, lojas ou rede de lojas com características similares a supermercados, que comercializam brinquedos, vestuário e outros produtos, cuja participação no ano-calendário anterior, seja superior a $10 \%$ da receita total.

Os setores que foram inicialmente beneficiados pela desoneração da folha de pagamento, com alíquotas sobre o faturamento que podem ser de $1 \%$ ou $2 \%$, segundo dados da revista Seguridade Social e Tributação (2014), foram definidos pela Medida Provisória $\mathrm{n}^{\circ}$ 540, de agosto de 2011, que contemplava alguns setores industriais e serviços de tecnologia da informação. 


\subsection{Impactos na arrecadação. Eficácia das medidas}

Muito se discute acerca dos impactos na arrecadação tributária no que concerne aos efeitos das medidas de desoneração tributária. Estudos feitos até agora apontam uma renúncia fiscal da ordem de $\mathrm{R} \$ 43,4$ bilhões de reais, segundo cálculos do Ministério da Fazenda, citados pela revista Seguridade Social e Tributação (2014, p.12).

Temos duas importantes questões que ora se apresentam decorrentes de tais medidas. Uma delas trata-se do real impacto nas contas públicas, conforme já mencionamos. A outra vertente desta história diz respeito aos repasses que deveriam ter sido feitos e à conta de quais valores.

A Lei 12.546/2013 prevê a compensação dos recursos subtraídos do orçamento da Seguridade Social mediante transferências do orçamento fiscal. Aí se acharia o descompasso. O governo federal alega que vem fazendo os repasses e na quantia correspondente ao retirado devido às desonerações. Por outro lado, entidades de classe e parlamentares afirmam que, além de haver um hiato temporal entre o que é retirado e o devolvido, haveria também a devolução em valores bem inferiores.

Num estudo sobre a desoneração da folha de salários, Alberto Luchiezi Jr. (2011, p.103), lança dúvidas sobre os efeitos benéficos que essa medida é capaz de promover. Os benefícios alardeados quando se trata de propostas de desoneração são a formalização das relações de trabalho e a manutenção da competividade do mercado externo. Segundo o autor, os efeitos benéficos dependeriam mais do desempenho positivo da economia e da melhor inserção competitiva das empresas no mercado globalizado.

A meu ver, em que pese a relevância de tais argumentos, esses não justificam a não implantação das desonerações pois estas seriam uma medida a mais no incremento do comércio exterior. Não se poderia deixar de implementá-las pelo simples motivo de que as mesmas, sozinhas, não surtiriam efeito.

O cerne do problema não é, se sozinhas ou não, as desonerações aumentariam a competividade do País no exterior, mas sim se os repasses estariam ou não sendo feitos e se na medida correta, como já comentado aqui.

Voltemos então aos impactos na arrecadação. É sabido que as receitas de exportações são constitucionalmente protegidas da tributação, inclusive da incidência das contribuições sociais. Como as receitas de exportações não integram a base de 
incidência das alíquotas substitutivas aplicadas sobre o faturamento, haveria um estímulo às exportações mas com um consequente impacto da arrecadação previdenciária. Vale dizer que o art. $8^{\circ}$ da Lei 12.546/2011 beneficiou com as medidas desonerativas na sua maior parte as indústrias, dentre as quais as extrativas e de transformação, notoriamente responsáveis por boa parte das receitas de exportações do País. Trata-se, portanto, de um verdadeiro paradoxo.

\section{CONCLUSÃO}

A política tributária de um país, conforme brevemente comentado no capítulo 1 deste trabalho, diz respeito à forma de arrecadar recursos que comporão suas receitas derivadas. A política de desonerações tributárias implementada, de maneira mais significativa a partir de 2011, objetivou alavancar o mercado formal de trabalho brasileiro e tornar mais competitivas suas exportações.

A forma como foi criada e desenvolvida toda essa política de incentivos é que se mostrou incorreta do ponto de vista jurídico, econômico e social. Senão vejamos.

Conforme podemos ter tido a oportunidade de observar, os orçamentos da seguridade social, o fiscal e o de investimento não se confundem. Esse é o disciplinamento da própria Constituição Federal. Na medida em que o próprio governo retira recursos advindos da seguridade social, o faz contra a lei maior. E o que é pior: não o faz na medida e tempo corretos. Isso faz com que o tão divulgado orçamento da seguridade social fique mais e mais deficitário.

Inicialmente, não se fez um estudo exaustivo sobre os setores a serem beneficiados pelas desonerações, o que fez com que setores pouco intensivos em mãode-obra e que têm um maior faturamento, tivessem prejuízos com a desoneração da folha.

Nos setores da economia que respondem por um maior volume de produtos exportados, diante da imunidade das receitas de exportação, houve um estímulo a tais setores porém com uma contrapartida negativa de arrecadação das contribuições sociais.

Outro problema diz respeito à escolha dos setores contemplados, já que ficou ao bel prazer do Poder Executivo toda a definição dos setores e produtos abrangidos. Não existiu qualquer discussão com a sociedade, beneficiária direta dessas medidas. 
Por fim, o governo ao abraçar medidas que visassem à melhora da economia, não o fez da forma correta, ignorando princípios básicos do Estado de Direito brasileiro, pensados de forma a propiciar uma melhoria na condição de vida de milhões.

\section{REFERÊNCIAS}

ASSOCIAÇÃO NACIONAL DOS AUDITORES-FISCAIS DA RECEITA FEDERAL DO BRASIL. Bondade com o chapéu alheio. Revista Seguridade Social e Tributação, Brasilia, ano 2014, p. 11-15,jan./mar. 2014.

DIEESE; IPEA; SINDIFISCO. A proguessividade na tributação brasileira: por maior justiça tributária e fiscal. Departamento Intersindical de Estatística e Estudos Socioeconômicos; Instituto de Pesquisa Econômica Aplicada; Sindifisco Nacional. São Paulo: DIEESE: IPEA: SINDIFISCO. 2011

FURTADO, J. R. Caldas. Elementos de Direito Financeiro. Belo Horizonte: Fórum, 2010

IBRAHIM, Fábio Zambitte. Curso de Direito Previdenciário. 18ed. Rio de Janeiro: Impetus, 2013.

LUCHIEZI JR, Álvaro. Desoneração da folha de salários: desconstruindo os mitos da formalização da mão-de-obra e da competividade industrial. RIBEIRO, José Aparecido Carlos, LUCHIEZI JR, Álvaro, MENDONÇA, Sérgio Eduardo Arlabu (Org). In: Proguessividade da Tributação e Desoneração da Folha de Pagamentos. Brasilia: IPEA: SINDIFISCO: DIEESE, 2011.

MACHADO, Hugo de Brito. Curso de Direito Constitucional Tributário. São Paulo: Malheiros Editores Ltda, 2015.

Curso de Direito Tributário. São Paulo: Malheiros Editores Ltda, 2015.

NEVES, Silvério das. VICECONTI, Paulo E. V. , SILVA JUNIOR, Francisco Aguiar. Curso Prático de Imposto de Renda Pessoa Jurídica e tributos conexos. São Paulo: Fiscosoft Editora, 2013.

OLIVEIRA, Carlindo Rodrigues. Encargos Sociais e Desoneração da Folha de Pagamentos: revisitando uma antiga polêmica. RIBEIRO, José Aparecido Carlos, LUCHIEZI JR, Álvaro, MENDONÇA, Sérgio Eduardo Arlabu (Org). In: 
Proguessividade da Tributação e Desoneração da Folha de Pagamentos. Brasilia: IPEA: SINDIFISCO: DIEESE, 2011.

OLIVEIRA, Regis Fernandes de. Curso de Direito Financeiro. São Paulo: Editora Revista dos Tribunais, 2010.

Séries Históricas e Estatísticas. IBGE. Disponível em http://seriesestatisticas.ibge.gov.br/series.aspx? vcodigo=SCN49\&t=carga-tributariabruta. Acesso em 30 out.2015

ZANGHELINI, Airton Nagel et al. Análise da desoneração definida na Lei 12.546/2011 e alterações posteriores. In: MAÇANEIRO, Vanderley José. Desoneração da Folha de Pagamentos. Oportunidade ou Ameaça? Brasilia: Associação dos Auditores-Fiscais da Receita Federal do Brasil e Fundação ANFIP de estudos da Seguridade Social, 2013. 